\title{
SELECTIVITY, TIMING AND THE PERFORMANCE OF LISTED PROPERTY TRUSTS: IMPLICATIONS FOR INVESTMENT STRATEGIES
}

\author{
VINCENT PENG \\ University of Western Sydney
}

\begin{abstract}
This study evaluates the performance of Australian Listed Property Trusts (LPTS) in the context of selectivity and timing over June 1998 to May 2003, and provides significant practical implications for investment strategies for LPT managers. The importance of benchmark indices and model specifications to performance evaluation is tested and highlighted in this paper. After specifying the appropriate model, the author has defined and constructed the appropriate benchmark indices for evaluating the performance of Australian LPTs. The study results provide evidence of superior strategic skills of Australian LPT managers over the study period based on study results.

This paper further illustrates the importance of longer-term market forecasts, especially in the circumstance where a lengthy time is required to apply timing skills. It suggests that managers who are superior in longer-term macro forecasts will have the edge to outperform the market portfolio and competitors, providing significant implications for investment decision-making. Finally, this paper demonstrates the importance of including the 'risk' factor in performance measurement and provides significant implications for market practitioners on how to avoid over/under-estimation of the true performance of a LPT.
\end{abstract}

\section{INTRODUCTION}

Listed Property Trusts (LPTs), as a successful investment vehicle in Australia, have enjoyed significant growth in the past ten years. Market capitalisation has grown by more than $23 \%$ per annum, rising from $\$ 6$ billion in 1993 to more than $\$ 50$ billion as at the end of May 2003 and now representing 7.6\% of the total Australian stock market (UBS Warburg, 2003). LPTs have gained their popularity not only from the diversification benefits they provide in a multi-asset portfolio as a unique asset class (eg, Newell et al, 2003; Wilson and Okunev, 1996, 1998), but also from the liquidity they provide as a listed vehicle and the appealing returns they present (see Table 1). 
Table 1: Performance of LPTs and other asset classes

\begin{tabular}{lcccc}
\hline \multicolumn{5}{c}{ Annualised Return to May 2003* } \\
\hline & One Year & Three Year & Five Year & Ten Year \\
\hline LPTs & $15.5 \%$ & $15.7 \%$ & $11.0 \%$ & $12.0 \%$ \\
Direct Property & $10.3 \%$ & $10.4 \%$ & $10.4 \%$ & $9.6 \%$ \\
All Ordinaries & $-6.6 \%$ & $3.0 \%$ & $5.6 \%$ & $9.6 \%$ \\
Bonds & $10.7 \%$ & $7.3 \%$ & $5.9 \%$ & $7.8 \%$ \\
\hline
\end{tabular}

Note: June 2003 for Direct Property

Source: Direct Property: PCA Investment Performance Index; All Ordinaries and LPTs: ASX Accumulation Series; Bonds: CBA All Series, All Maturities Accumulation Series.

As a listed asset, LPTs are inevitably influenced by financial market fluctuations. However, as a defensive listed asset with a focus on distributions as opposed to capital growth, the performance of a LPT is driven and determined by the fundamentals of its underlying income generators, ie. the underlying direct property portfolio. Successful asset and property management will add value to a property portfolio; however, the superiority of a property portfolio is largely underpinned by how well the portfolio is constructed (for example, by sector, location and lease structure), relying on the investment strategies undertaken by LPT managers.

The formation of good investment strategies requires superior forecasting skills, both micro forecasting and macro forecasting. Micro forecasting skills refer to the ability of an investment manager to identify and exploit undervalued property assets. That is, whether the portfolio has included the right properties (selectivity). In terms of new acquisitions, whether undervalued assets have been identified and included in the portfolio, and in terms of disposals, whether under performing assets have been identified and excluded. Macro forecasting skills refer to the ability of an investment manager to position the property portfolio to take advantage of predicted market movements. That is, whether an investment manager has executed these acquisitions and disposals at the right time (timing).

Several studies have been conducted to evaluate the performance of overseas real estate portfolios in the context of selectivity and timing. These studies include Gallo et al (1997, 2000), Myer and Webb (2000), and O'Neal and Page (2000) for US REITs, real estate mutual funds and Mortgage Backed Securities (MBS); Lee (1997) and Lee and Stevenson (2002) for UK real estate funds; Stevenson et al (1997) and Lee and Stevenson (2001) for Irish based real estate funds; and Liow (2001) for Singapore property companies.

The results from these studies are inconclusive. For example, while some found the superior performance is attributed to selectivity rather than timing (Lee, 1997; Lee and Stevenson, 2002), others found superior performance is attributed to timing 
rather than selectivity (Gallo et al, 2000; Stevenson et al, 1997) or there is lack of superior returns that can be attributed to either property selection or market timing (Gallo et al, 1997; Liow, 2001; O’Neal and Page, 2000).

For Australian LPTs, only one study (Newell et al, 2003) has been found in the literature search. Newell et al (2003) used the PCA ${ }^{1}$ composite property index as the market benchmark and found that superior performance of LPTs was more attributable to selectivity rather than timing. However, the use of PCA index as the benchmark index is potentially problematic.

Firstly, the PCA index is based on the performance of direct properties that are unlisted assets. The vast and distinct differences between the two forms of real estate (listed and unlisted) have been well demonstrated and documented (Newell and MacFarlane, 1996; Seiler et al, 1999; Myer and Webb, 1993; Barkham and Geltner, 1995). To compare like with like, an index based on listed properties, such as the Australian Stock Exchange (ASX) LPT 300 index (LPT 300), will be a more appropriate benchmark than the PCA index. Secondly, the Australian LPT market is composed of LPTs in five sub-sectors: Commercial, Retail, Industrial, Hotel and Diversified and each sub-sector has different risk/return profiles and market fundamentals. For example, as evidenced in recent years, a significant positive yield shift has driven up the performance of retail and industrial assets but not commercial assets. As such, the LPT 300, as a 'composite' index, may not be appropriate because it will not be able to differentiate distinct drivers in different sub-sectors. Therefore, for a LPT in a certain sub-sector, an index specific to that sub-sector should be considered as the benchmark index. Furthermore, since the Australian LPT market is thin, the performance of each LPT, especially those with large market capitalisations, will have a significant impact on the market index. This impact will become more significant at the sub-sector level (ie. sub-sector market indices), which is highly likely to distort the evaluation results. The above three propositions are tested in this paper and all found to be supported.

The remainder of this paper is structured as follows. Section two briefly describes the three commonly used techniques for the evaluation of selectivity and timing, and explains the methods used for this study. Section three introduces how the data is compiled, covering LPT returns, benchmark indices and risk-free rates. Empirical findings are then analysed in section four, and the last section provides concluding comments.

\section{METHODOLOGY}

This section introduces the three commonly used techniques for evaluating fund performance in the context of selectivity and timing. These are Jensen (1968),

${ }^{1}$ Property Council of Australia

Pacific Rim Property Research Journal, Vol 10, No 2 
Henriksson and Merton (1981) and Treynor and Mazuy (1966). It also demonstrates how the model is specified for this study.

\section{Jensen (1968)}

Based on the framework of Sharpe's (1964) Capital Asset Pricing Model (CAPM), Jensen (1968) expressed the excess return as follows:

$$
\mathrm{R}_{\mathrm{pt}}-\mathrm{R}_{\mathrm{ft}}=\beta\left(\mathrm{R}_{\mathrm{Mt}}-\mathrm{R}_{\mathrm{ft}}\right)+\varepsilon_{\mathrm{t}}
$$

where:

$\mathrm{R}_{\mathrm{pt}}$ is the portfolio return at time $\mathrm{t}$

$\mathrm{R}_{\mathrm{ft}}$ is the risk free rate at time $\mathrm{t}$

$\mathrm{R}_{\mathrm{Mt}}$ is the market return at time $\mathrm{t}$

$\beta$ is the portfolio systematic risk

$\varepsilon_{t}$ is a random error term that has the expected value of zero.

If the investment manager has superior selection skills, the random error term in equation (1) will be greater than zero, ie., the portfolio will achieve excess returns greater than expected given its level of systematic risk. Equation (2) takes its form by not constraining the estimated regression and adding an intercept to equation (1), and is the most commonly used form of Jensen's (1968) model.

$$
\mathrm{R}_{\mathrm{pt}}-\mathrm{R}_{\mathrm{ft}}=\alpha+\beta\left(\mathrm{R}_{\mathrm{Mt}}-\mathrm{R}_{\mathrm{ft}}\right)+\varepsilon_{\mathrm{t}}
$$

The new error term will now have an expected value of zero and the intercept (Jensen's $\alpha$ ) is interpreted as superior (inferior) return performance attributable to the selection skills of the fund manager.

Equation (2) assumes that the portfolio's $\beta$ is constant throughout the period of evaluation. However, if the portfolio is actively managed, the portfolio $\beta$ will change over time, then equation (2) will be mis-specified. Fama (1972) and Jensen (1972) observed that the application of simple regression techniques to calculate the Jensen index of performance will be biased and any test of significance distorted (Lee, 1997). Empirical studies (Grant, 1977; Lee and Rahman, 1990; Chang and Lewellen, 1984; Henriksson, 1984) show that tests focusing solely on selection skills will cause the estimate of $\alpha$ to be downward biased. That is, the estimated value of selectivity is lower when timing is ignored than when timing is accounted for. This highlights that fund managers need to be evaluated on both selectivity and timing.

Henriksson and Merton (1981)

Henriksson and Merton (1981) extended Jensen (1968) and decomposed performance into selectivity and timing as follows: 


$$
\mathrm{R}_{\mathrm{pt}}-\mathrm{R}_{\mathrm{ft}}=\alpha+\beta\left(\mathrm{R}_{\mathrm{Mt}}-\mathrm{R}_{\mathrm{ft}}\right)+\gamma\left[\mathrm{D}\left(\mathrm{R}_{\mathrm{Mt}}-\mathrm{R}_{\mathrm{ft}}\right)\right]+\varepsilon_{\mathrm{t}}
$$

where:

$D$ is a dummy variable taking the value of 0 when $R_{M t}>R_{f t}$ and a value of 1 when $\mathrm{R}_{\mathrm{Mt}} \leq \mathrm{R}_{\mathrm{ft}}$.

$\alpha$ is the measure of the investment manager's selection ability

$\gamma$ is the coefficient estimating market timing ability

and all other variables are as defined immediately above.

The advantage of Henriksson and Merton (1981) over Jensen (1968) is that it is possible to explicitly test for selectivity based on $\alpha$ and timing based on $\gamma$. However, with the inclusion of a dummy variable $\mathrm{D}$, the empirical relationship between $R_{p t}$ and $R_{M t}$ is made up of two regression regimes in which the slope coefficient is $\beta$ in a bull market $\left(R_{M t}>R_{f t}\right)$ and becomes $(\beta-\gamma)$ in a bear market $\left(\mathrm{R}_{\mathrm{Mt}} \leq \mathrm{R}_{\mathrm{ft}}\right)$. As a result, the error term may be subject to heteroscadasticity that would distort the efficiency of Ordinary Least Square (OSL) estimation of the model parameters ${ }^{2}$. Empirical work by Lee (1997), Henriksson (1984), Breen et al (1986) have addressed the necessity of making some adjustment for heteroscadasticity in models such as Henriksson and Merton (1981).

\section{Treynor and Mazuy (1966)}

An alternative method is Treynor and Mazuy (1966) as expressed in the following equation:

$$
\mathrm{R}_{\mathrm{pt}}-\mathrm{R}_{\mathrm{ft}}=\alpha+\beta\left(\mathrm{R}_{\mathrm{Mt}}-\mathrm{R}_{\mathrm{ft}}\right)+\gamma\left(\mathrm{R}_{\mathrm{Mt}}-\mathrm{R}_{\mathrm{ft}}\right)^{2}+\varepsilon_{\mathrm{t}}
$$

In a standard CAPM regression equation, a portfolio's return $\left(R_{p}\right)$ is a linear function of the market return $\left(\mathrm{R}_{\mathrm{M}}\right)$. However, if the investment manager has macro forecasting ability, he will hold a greater proportion of the market portfolio in a bull market and a smaller proportion in a bear market. Consequently, as argued by Treynor and Mazuy (1966), the portfolio return is a convex function of the market return, captured by the coefficient $\gamma$ on the quadratic term in equation (4). A further theoretical justification for equation (4) can be found in Admati et al (1986).

This study uses the non-linear specification of Treynor and Mazuy (1966) to evaluate selectivity and timing skills of LPT managers. Another reason for considering a non-linear specification is that all Australian LPTs are geared, with an average gearing level of $26 \%$ (PIR, 2003). Returns from geared securities follow a non-linear function and the linear specification, such as equation (4), will lead to

${ }^{2}$ Heteroscedasticity causes the standard error to be incorrect, thereby invalidating tests, such as t-test for each of the parameter estimates.

Pacific Rim Property Research Journal, Vol 10, No 2 
biased results. Jagannathan and Korajczyk (1986) provided additional insights on the non-linear function of returns from geared securities.

In this study, Treynor and Mazuy (1966) assume the following form to account for the use of sub-sector specific market indices as discussed in the introduction section:

$$
\mathrm{R}_{\mathrm{LPTit}}-\mathrm{R}_{\mathrm{ft}}=\alpha_{\mathrm{i}}+\beta_{\mathrm{i}}\left(\mathrm{R}_{\mathrm{INDEXit}}-\mathrm{R}_{\mathrm{ft}}\right)+\gamma_{\mathrm{i}}\left(\mathrm{R}_{\mathrm{INDEXit}}-\mathrm{R}_{\mathrm{ft}}\right)^{2}+\varepsilon_{\mathrm{it}}
$$

where:

$\mathrm{R}_{\text {LPTit }}$ is the return on LPT $\mathrm{i}$ at month $\mathrm{t}$

$\mathrm{R}_{\mathrm{ft}}$ is the risk free rate at month $\mathrm{t}$

$\mathrm{R}_{\text {INDEXit }}$ is the return on the benchmark index specific for LPT $i$ at month $t$.

LPT managers exhibit superior micro forecasting (selectivity) and macro forecasting (timing) skills if both $\alpha_{i}$ and $\gamma_{i}$ in the above model are positive and statistically significant.

In this study, parameter estimates are corrected using the procedures of White (1980) in the presence of heteroscedasticity.

\section{DATA}

\section{LPT returns}

The performance evaluation was undertaken on 18 LPTs with complete monthly movement information over the 60-month period from June 1998 through May 2003.

As at the end of May 2003, there were 30 LPTs included in LPT 300, representing a market capitalisation of $\$ 50.5$ billion and $7.6 \%$ of the total Australian stock market. Of these 30 LPTs, 12 were excluded, as they were launched after June 1998 and did not have an adequate time series to be included in this study. Since June 1998, 27 UBS-tracked LPTs disappeared from the market, resulting from the significant merger and acquisition activity in the LPT sector over this period.

The remaining 18 LPTs had 645 investment grade properties across Australia, New Zealand and US (Property Investment Research, 2003), accounting for $79 \%$ by market capitalisation of the LPT 300 as at the end of May 2003. They represented all LPT sub-sectors, with five in the Commercial sub-sector, five in the Retail subsector, two in the Industrial sub-sector, two in the Hotel sub-sector and four in the Diversified sub-sector. 
Table 2 provides further details of the 18 LPTs included in this study.

Based on the UBS Warburg LPT accumulation indices, simple annual returns (as opposed to logarithmic returns) were calculated for each of the 60 months and used in this study to conform to the common practices in the marketplace. ${ }^{3}$

Table 2:LPT summaries

\begin{tabular}{|c|c|c|c|c|c|c|}
\hline & Code & Sector & $\begin{array}{c}\text { Market } \\
\text { Capitalisation } \\
(\$ \mathrm{~m}) \\
\end{array}$ & $\begin{array}{l}\text { Index } \\
\text { Weight }\end{array}$ & $\begin{array}{c}\text { No of } \\
\text { Properties }\end{array}$ & $\begin{array}{c}\text { Five Year } \\
\text { Performance } \\
\text { (June98-May03) }\end{array}$ \\
\hline AMP Office Trust & $\mathrm{AOF}$ & Commercial & 879.2 & $1.7 \%$ & 12 & $8.0 \%$ \\
\hline Principal Office Fund & POF & Commercial & 1538.8 & $3.0 \%$ & 12 & $9.8 \%$ \\
\hline ING Office Fund & IOF & Commercial & 851.1 & $1.7 \%$ & 18 & $8.7 \%$ \\
\hline Investa Property Group & IPG & Commercial & 1808.4 & $3.6 \%$ & 29 & $12.8 \%$ \\
\hline Macquarie Office Trust & MOF & Commercial & 1064.2 & $2.1 \%$ & 22 & $10.1 \%$ \\
\hline Centro Properties Group & CEP & Retail & 1917.6 & $3.8 \%$ & 27 & $18.3 \%$ \\
\hline Gandel Retail Trust & GAN & Retail & 1722.0 & $3.4 \%$ & 20 & $11.7 \%$ \\
\hline $\begin{array}{l}\text { Macquarie CountryWide } \\
\text { trust }\end{array}$ & $\mathrm{MCW}$ & Retail & 804.2 & $1.6 \%$ & 109 & $13.0 \%$ \\
\hline Westfield America Trust & WFA & Retail & 6340.1 & $12.5 \%$ & 62 & $15.0 \%$ \\
\hline Westfield Trust & WFT & Retail & 7585.4 & $15.0 \%$ & 40 & $8.9 \%$ \\
\hline AMP Industrial Trust & AIP & Industrial & 372.0 & $0.7 \%$ & 26 & $11.7 \%$ \\
\hline ING Industrial Fund & IIF & Industrial & 1051.6 & $2.1 \%$ & 54 & $13.5 \%$ \\
\hline Grand Hotel Group & GHG & Hotel & 78.4 & $0.2 \%$ & 25 & $-14.7 \%$ \\
\hline Thakral Holdings Group & THG & Hotel & 165.7 & $0.3 \%$ & 17 & $9.5 \%$ \\
\hline $\begin{array}{l}\text { AMP Diversified } \\
\text { Property Trust }\end{array}$ & $\mathrm{ADP}$ & Diversified & 1620.8 & $3.2 \%$ & 34 & $12.2 \%$ \\
\hline $\begin{array}{l}\text { Deutsche Diversified } \\
\text { Fund }\end{array}$ & DDF & Diversified & 1138.0 & $2.3 \%$ & 26 & $7.5 \%$ \\
\hline General Property Trust & GPT & Diversified & 6005.4 & $11.9 \%$ & 51 & $8.9 \%$ \\
\hline Stockland Trust Group & SGP & Diversified & 4721.2 & $9.3 \%$ & 61 & $14.2 \%$ \\
\hline
\end{tabular}

Source: UBS Warburg (2003)

\section{Benchmark indices}

The benchmark indices examined in this study include the LPT 300, LPT 300 subsector indices (ie. Commercial 300, Retail 300, Industrial 300, Hotel 300 and Diversified 300) as well as the ex-indices based on LPT 300 sub-sector indices but excluding the LPT currently under evaluation.

\footnotetext{
${ }^{3}$ Logarithmic returns were suggested by Lee (1997) to account for the tendency of significant positive skewness and leptokurtic distribution of simple returns for property data (Brown, 1987; and Myer and Webb, 1993) as well as the 'appraisal bias' introduced to the data when pricing was based on valuation and not 'true' market price (a dominant case for pricing property and property funds). However, in this study, both LPT returns and market index returns are based on market transactions and thus 'appraisal bias' is less an issue. Also, the distribution of simple returns was tested by the author and showed little difference from that of logarithmic returns.
}

Pacific Rim Property Research Journal, Vol 10, No 2 
Both LPT 300 and LPT 300 sub-sector indices are sourced from UBS Warburg. The ex-indices are constructed by the author using the following method:

$$
\operatorname{ExR}_{\text {INDEXit }}=\left(\mathrm{R}_{\text {INDEXit }}-\mathrm{R}_{\mathrm{LPTit}} * \mathrm{~W}_{\mathrm{LPTit}}\right) /\left(1-\mathrm{W}_{\mathrm{LPTit}}\right)
$$

where:

ExR $_{\text {INDEXit }}$ is the LPT 300 sub-sector ex-index return at month $\mathrm{t}$

$\mathrm{R}_{\text {INDEXit }}$ is the LPT 300 sub-sector (specific to LPT i) index return at month $\mathrm{t}$

$\mathrm{R}_{\mathrm{LPTit}}$ is the return for LPT $\mathrm{i}$ at month $\mathrm{t}$

$\mathrm{W}_{\text {LPTit }}$ is LPT $\mathrm{i}$ market capitalisation as a percentage of LPT 300 market capitalisation at month $t$, ie. the weight of LPT $i$ at month $t$.

The following table presents the different return profiles for these three types of indices.

Table 3: Benchmark indices

\begin{tabular}{lc}
\hline \multicolumn{1}{c}{ Index } & $\begin{array}{c}\text { Five Year Performance } \\
\text { (June 98-May 03) }\end{array}$ \\
\hline LPT300 & $11.0 \%$ \\
Commercial 300 & $9.5 \%$ \\
Retail 300 & $11.3 \%$ \\
Industrial 300 & $13.7 \%$ \\
Hotel 300 & $0.3 \%$ \\
Diversified 300 & $11.3 \%$ \\
Commercial 300 ex AOF & $9.7 \%$ \\
Commercial 300 ex POF & $9.3 \%$ \\
Commercial 300 ex IOF & $9.6 \%$ \\
Commercial 300 ex IPG & $8.9 \%$ \\
Commercial 300 ex MOF & $9.4 \%$ \\
Retail 300 ex CEP & $10.7 \%$ \\
Retail 300 ex GAN & $11.2 \%$ \\
Retail 300 ex MCW & $11.2 \%$ \\
Retail 300 ex WFA & $10.0 \%$ \\
Retail 300 ex WFT & $12.8 \%$ \\
Industrial 300 ex AIP & $14.0 \%$ \\
Industrial 300 ex IIF & $13.7 \%$ \\
Hotel 300 ex GHG & $12.5 \%$ \\
Hotel 300 ex THG & $-11.2 \%$ \\
Diversified 300 ex ADP & $11.1 \%$ \\
Diversified 300 ex DDF & $11.5 \%$ \\
Diversified 300 ex GPT & $12.6 \%$ \\
Diversified 300 ex SGP & $10.3 \%$ \\
\hline
\end{tabular}




\section{Risk free rates}

Ninety-day Treasury Bills are the commonly used risk-free standard in empirical studies within the CAPM framework. In Australia, rates on 90-day Treasury Notes (T-Note) can be sourced from the Reserve Bank of Australia (RBA). However, the T-Note series stopped in June 2002 and Overnight Indexed Swap Rates (OISR) were provided instead by RBA since then. In this study, we use T-Note and OISR (in the absence of T-Note) as the risk free series. Details of OISR and justifications of using it as the substitute for T-Note can be found in RBA (2002).

\section{RESULTS AND ANALYSIS}

\section{Benchmark indices and model specification} LPT 300

Table 4 presents the evaluation results using Treynor and Mazuy (TM) model, specified in equation (4), and LPT 300 as the benchmark index.

Table 4: LPT selectivity and timing analysis: June 1998 - May 2003 (LPT 300 Index as the benchmark index)

\begin{tabular}{|c|c|c|c|c|c|c|c|}
\hline & \multicolumn{3}{|c|}{ Selectivity } & \multicolumn{3}{|c|}{ Timing } \\
\hline & & Coefficient & Rank & t-Statistics & Coefficient & Rank & t-Statistics \\
\hline $\mathrm{AOF}$ & Commercial & -0.0396 & 17 & $-3.8941 * * *$ & 1.8051 & 6 & 1.5580 \\
\hline POF & Commercial & -0.0286 & 15 & {$[-1.8750] *$} & 1.6351 & 7 & [1.0344] \\
\hline IOF & Commercial & -0.0072 & 10 & {$[-0.9226]$} & 0.9824 & 10 & {$[0.9255]$} \\
\hline IPG & Commercial & 0.0050 & 9 & {$[0.3316]$} & 1.9064 & 5 & {$[1.0532]$} \\
\hline MOF & Commercial & 0.0055 & 8 & {$[0.5415]$} & 3.0398 & 3 & {$[1.9937] *$} \\
\hline CEP & Retail & 0.0615 & 2 & {$[7.5748] * * *$} & 3.3353 & 2 & {$[2.9502] * * *$} \\
\hline GAN & Retail & 0.0164 & 7 & {$[1.3813]$} & -2.1061 & 16 & {$[-1.5439]$} \\
\hline $\mathrm{MCW}$ & Retail & 0.0165 & 6 & 1.0814 & 4.0243 & 1 & $2.3155 * *$ \\
\hline WFA & Retail & 0.0276 & 3 & 1.4995 & 1.5136 & 9 & 0.7210 \\
\hline WFT & Retail & -0.0089 & 11 & -0.6916 & -0.6352 & 14 & -0.4336 \\
\hline AIP & Industrial & -0.0090 & 12 & -0.6380 & 1.9660 & 4 & 1.2186 \\
\hline IIF & Industrial & 0.0221 & 4 & {$[2.8225] * * *$} & 1.6229 & 8 & {$[1.8041] *$} \\
\hline GHG & Hotel & -0.1230 & 18 & $-5.7328 * * *$ & -3.9924 & 18 & -1.6329 \\
\hline THG & Hotel & 0.0978 & 1 & {$[2.9052] * * *$} & 0.3706 & 12 & {$[0.1305]$} \\
\hline $\mathrm{ADP}$ & Diversified & -0.0116 & 13 & -1.2944 & 0.4142 & 11 & 0.4054 \\
\hline DDF & Diversified & -0.0305 & 16 & $-2.7454 * * *$ & 0.2945 & 13 & 0.2327 \\
\hline GPT & Diversified & -0.0196 & 14 & {$[-3.8144] * * *$} & -1.4617 & 15 & {$[-1.9154] *$} \\
\hline SGP & Diversified & 0.0211 & 5 & $2.0138 * *$ & -3.2355 & 17 & $-2.7136 * * *$ \\
\hline \multicolumn{2}{|c|}{ Average } & -0.0003 & & & 0.6377 & & \\
\hline \multicolumn{2}{|c|}{ Positive } & 9 & & & 13 & & \\
\hline \multirow{2}{*}{\multicolumn{2}{|c|}{$\begin{array}{l}\text { Negative } \\
\text { Significantly Positive }\end{array}$}} & 9 & & & 5 & & \\
\hline & & 4 & & & 4 & & \\
\hline \multicolumn{2}{|c|}{ Significantly Negative } & 5 & & & 2 & & \\
\hline
\end{tabular}

*** significant at 1\% level; ** significant at 5\% level; * significant at $10 \%$ level. 
The values of t-statistics in brackets are the White [1980] adjusted t-statistics in the presence of heteroscedasticity

Nine LPTs displayed positive selection ability with four LPTs showing significant positive selection ability (CEP, IIF, THG and SGP). Thirteen LPTs showed positive timing ability with four being significant (MOF, CEP, MCW and IIF).

As the results showed, no LPTs in the Commercial sub-sector had presented significant selection ability. The lack of superior selectivity in the Commercial subsector may simply be because all the Commercial LPTs under evaluation have been penalised by the fact that the Commercial sub-sector as a whole has not performed so well as the other sub-sectors. If this is the case, LPT 300 (as a composite index) will not be the appropriate benchmark index for evaluating the performance of sector-specific LPTs and any evaluation results may be distorted.

Over the period of June 1998 to May 2003, Industrial and Retail LPTs have been strongly supported by investors, generating double-digit annualised returns of $14.3 \%$ and $11.7 \%$ respectively, a significant premium compared to $9.5 \%$ for Commercial LPTs. The following figure explains why investors are in favor of Industrial and Retail LPTs by showing the relative performance of the underlying direct property assets in the selected three sub-sectors. Figure 1 clearly shows the relative underperformance of Commercial property assets.

Figure 1: Direct property performance (June 1998 to June 2003)

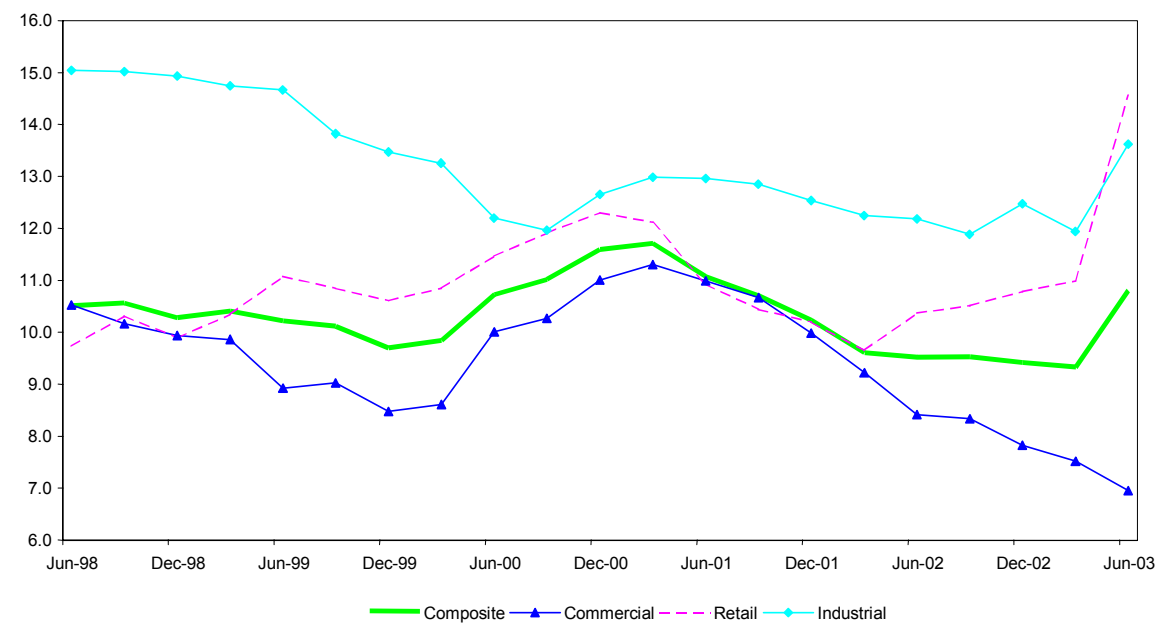

Source: PCA (2003) 
LPT 300 sub-sector indices

Table 5 presents the evaluation results using TM model and 'purified' benchmark indices to remove the impacts not relevant to the LPT under evaluation, e.g., using Commercial 300 for Commercial LPTs and Retail 300 for Retail LPTs.

Table 5: LPT selectivity and timing analysis: June 1998 - May 2003 (LPT 300 sub-sector indices as the benchmark indices)

\begin{tabular}{|c|c|c|c|c|c|c|c|c|c|}
\hline & \multicolumn{4}{|c|}{ Selectivity } & \multicolumn{4}{|c|}{ Timing } \\
\hline & & Coefficient & Rank & t-Statistics & & Coefficient & Rank & t-Statistics & \\
\hline $\mathrm{AOF}$ & Commercial & -0.0159 & 11 & -2.0204 & ** & 1.1032 & 7 & 0.8455 & \\
\hline POF & Commercial & -0.0204 & 13 & -2.7134 & $* * *$ & -1.2252 & 18 & -0.9802 & \\
\hline IOF & Commercial & 0.0123 & 8 & 1.6606 & & -0.2262 & 13 & -0.1839 & \\
\hline IPG & Commercial & 0.0187 & 4 & 2.8799 & $* * *$ & -1.1267 & 17 & -1.0482 & \\
\hline MOF & Commercial & 0.0153 & 7 & 2.4645 & $* *$ & 1.5186 & 5 & 1.4779 & \\
\hline CEP & Retail & 0.0833 & 2 & [11.7614] & $* * *$ & -0.1695 & 12 & {$[-0.3786]$} & \\
\hline GAN & Retail & 0.0041 & 10 & [0.5683] & & -0.4082 & 14 & {$[-1.1914]$} & \\
\hline MCW & Retail & 0.0222 & 3 & 1.9790 & $*$ & 1.0918 & 8 & 1.7550 & * \\
\hline WFA & Retail & 0.0178 & 5 & 2.3964 & $* *$ & 1.1894 & 6 & 2.8904 & $* * *$ \\
\hline WFT & Retail & -0.0206 & 14 & {$[-3.9433]$} & $* * *$ & 0.4072 & 9 & [1.3975] & \\
\hline AIP & Industrial & -0.0225 & 16 & {$[-2.1973]$} & $* *$ & 2.8109 & 2 & [2.0474] & $* *$ \\
\hline IIF & Industrial & 0.0086 & 9 & 1.5899 & & 1.6961 & 4 & 2.3133 & $* *$ \\
\hline GHG & Hotel & -0.1926 & 18 & -10.6584 & $* * *$ & 3.2324 & 1 & 2.6883 & $* * *$ \\
\hline THG & Hotel & 0.1144 & 1 & 5.4023 & $* * *$ & -0.8919 & 16 & -0.6326 & \\
\hline ADP & Diversified & -0.0183 & 12 & -2.2474 & $* *$ & 1.8864 & 3 & 2.5777 & ** \\
\hline DDF & Diversified & -0.0232 & 17 & -1.8686 & $*$ & 0.2687 & 10 & 0.2410 & \\
\hline GPT & Diversified & -0.0221 & 15 & -4.6223 & $* * *$ & -0.0025 & 11 & -0.0059 & \\
\hline SGP & Diversified & 0.0160 & 6 & 1.7333 & * & -0.8456 & 15 & -1.0196 & \\
\hline \multicolumn{2}{|c|}{ Average } & -0.0013 & & & & 0.5727 & & & \\
\hline \multicolumn{2}{|c|}{ Positive } & 10 & & & & 10 & & & \\
\hline \multicolumn{2}{|c|}{ Negative } & 8 & & & & 8 & & & \\
\hline \multirow{2}{*}{\multicolumn{2}{|c|}{$\begin{array}{l}\text { Significantly Positive } \\
\text { Sionificantly Neoative }\end{array}$}} & 7 & & & & 6 & & & \\
\hline & & 8 & & & & 0 & & & \\
\hline
\end{tabular}

The values of t-statistics in brackets are the White [1980] adjusted t-statistics in the presence of heteroscedasticity.

Now, there are ten LPTs showing positive selection ability and the number of LPTs showing significantly positive selection ability has increased to seven from four. As expected, by using the LPT 300 sub-sector indices, some Commercial LPTs (IPG and MOF) illustrate significant superior selectivity ability. The number of 
LPTs showing superior timing ability also changed. Ten LPTs showed positive timing ability, six of which are significantly positive.

However, the use of LPT 300 sub-sector indices may introduce a problem. Given that the Australian LPT market is thin, the performance of each LPT, especially those with large market capitalisations, may have a significant impact on the market index. This impact will become especially significant at the LPT sub-sector level. This again is likely to distort the evaluation results.

Table 6: LPT selectivity and timing analysis: June 1998 - May 2003 (LPT 300 sub-sector ex-indices as the benchmark indices)

\begin{tabular}{|c|c|c|c|c|c|c|c|c|c|}
\hline & & \multicolumn{4}{|c|}{ Selectivity } & \multicolumn{4}{|c|}{ Timing } \\
\hline & & Coefficient & Rank & t-Statistics & & Coefficient & Rank & Statistics & \\
\hline AOF & Commercial & -0.0172 & 14 & -1.9784 & $*$ & 2.1968 & 3 & 1.6109 & \\
\hline POF & Commercial & -0.0201 & 15 & -2.2943 & $* *$ & -1.5622 & 17 & -1.0777 & \\
\hline IOF & Commercial & 0.0155 & 8 & 1.9429 & $*$ & -0.5007 & 14 & -0.3997 & \\
\hline IPG & Commercial & 0.0249 & 4 & 2.9911 & $* * *$ & -0.3532 & 11 & -0.2297 & \\
\hline MOF & Commercial & 0.0179 & 6 & 2.5808 & $* *$ & 1.7017 & 4 & 1.5511 & \\
\hline CEP & Retail & 0.0906 & 1 & [11.4971] & $* * *$ & -0.3664 & 13 & {$[-0.7928]$} & \\
\hline GAN & Retail & 0.0074 & 9 & [0.8886] & & -0.6059 & 15 & {$[-1.4471]$} & \\
\hline MCW & Retail & 0.0236 & 5 & 2.0534 & $* *$ & 1.1316 & 6 & 1.8223 & * \\
\hline WFA & Retail & 0.0412 & 2 & [4.1719] & $* * *$ & 0.8601 & 8 & [1.7851] & * \\
\hline WFT & Retail & -0.0166 & 12 & {$[-1.8501]$} & * & -0.2841 & 10 & {$[-0.3676]$} & \\
\hline AIP & Industrial & -0.0170 & 13 & -1.4108 & & 3.6453 & 1 & 2.1908 & $* *$ \\
\hline IIF & Industrial & 0.0162 & 7 & 2.1725 & $* *$ & 2.4908 & 2 & 2.3021 & ** \\
\hline GHG & Hotel & $-\mathbf{0 . 1 7 0 7}$ & 18 & -9.5255 & $* * *$ & 0.0203 & 9 & 0.0531 & \\
\hline THG & Hotel & -0.0203 & 16 & {$[-0.8950]$} & & 1.0677 & 7 & [2.0565] & $* *$ \\
\hline $\mathrm{ADP}$ & Diversified & -0.0157 & 10 & -1.6933 & $*$ & 1.6521 & 5 & 2.0139 & $* *$ \\
\hline DDF & Diversified & -0.0165 & 11 & -1.2280 & & -0.3570 & 12 & -0.2998 & \\
\hline GPT & Diversified & -0.0236 & 17 & -3.1045 & $* * *$ & -1.1296 & 16 & -1.5453 & \\
\hline SGP & Diversified & 0.0405 & 3 & 3.6027 & $* * *$ & -3.1081 & 18 & -2.6506 & $* *$ \\
\hline \multicolumn{2}{|c|}{ Average } & -0.0022 & & & & 0.3611 & & & \\
\hline \multicolumn{2}{|c|}{ Positive } & 9 & & & & 9 & & & \\
\hline \multicolumn{2}{|c|}{ Negative } & 9 & & & & 9 & & & \\
\hline \multicolumn{2}{|c|}{ Significantly Positive } & 8 & & & & 6 & & & \\
\hline \multicolumn{2}{|c|}{ Significantly Negative } & 6 & & & & 1 & & & \\
\hline
\end{tabular}

*** significant at $1 \%$ level; $* *$ significant at $5 \%$ level; * significant at $10 \%$ level.

The values of t-statistics in brackets are the White [1980] adjusted t-statistics in the presence of heteroscedasticity. 
An extreme example is WFT in the Retail sub-sector. With a market capitalisation of $\$ 7.59$ billion as at the end of May 2003, WFT contributes almost 38\% to the Retail 300 (market capitalisation of $\$ 19.96$ billion). Therefore, the performance of the Retail 300 will be significantly and inevitably influenced by the performance of WFT. In other words, WFT will be benchmarked, to some extent, against its own performance if Retail 300 is used directly, which will cause all evaluation results to be distorted. To overcome this, a new sub-sector index needs to be derived to remove the impact of WFT (ie., Retail 300 excluding WFT) when evaluating the performance of WFT.

LPT 300 sub-sector ex-indices

Following the method explained in section 3.2, new sub-sector benchmark indices (LPT 300 sub-sector ex-indices) have been compiled to exclude the impact of the LPT under evaluation. Table 6 presents the results from the TM model using these new indices.

Again, as expected, the results are largely different from those in Table 5. There are now nine LPTs showing positive selection ability, eight of which showing significantly positive selection ability. Also, as expected, the market timing has vastly different profiles in the three tables.

Sections 4.1.1, 4.1.2 and 4.1.3 tested and compared the results from the same model but using different benchmark indices. It demonstrated the importance of using the appropriate benchmark indices in the evaluation of fund performance.

\section{Model specification}

Table 7 presents the results from Jensen's model using LPT sub-sector ex-indices.

The average $\alpha$ from Jensen's model is $-0.28 \%$ and is 6 basis points lower than that from the TM model $(-0.22 \%)$, a result consistent with previous studies (Grant, 1977; Lee and Rahman, 1990; Chang and Lewellen, 1984; Henriksson, 1984). This confirms that the LPTs under evaluation have been actively managed and the thus the portfolio risks relative to the market portfolio do change over time. In such a case, any evaluation of selectivity based on Jensen's model will be biased and a model such as TM model should be used to explicitly split selection and timing skills to achieve accurate assessment.

The strong negative correlation between selection and timing documented in previous studies (for example, Lee, 1997; Connor and Korajczyk, 1991; Chan and Chen, 1992; Chang and Lewellen, 1984; Henriksson, 1984) is not evidenced in this study.

As shown in Table 6, almost half (8 out of 18) LPTs under review showed positive selection ability coupled with positive timing skills (4) or negative selectivity 
coupled with negative timing (4). Explanations proposed for the strong negative relationship between selection and timing abilities include mis-specification of the market portfolio and linear specification of the model (Lee, 1997; Henriksson, 1984; Janannathan and Korajczyk, 1986).

Table 7: Jensen's model

\begin{tabular}{|c|c|c|c|c|c|}
\hline & \multicolumn{3}{|c|}{ Jensen's $\alpha$} & \\
\hline & & Coefficient & Rank & $\mathrm{t}$-Statistics & \\
\hline AOF & Commercial & -0.0112 & 11 & {$[-1.2436]$} & \\
\hline POF & Commercial & -0.0235 & 15 & -2.8516 & $* * *$ \\
\hline IOF & Commercial & 0.0141 & 8 & 1.9832 & * \\
\hline IPG & Commercial & 0.0240 & 4 & [3.0318] & $* * *$ \\
\hline MOF & Commercial & 0.0228 & 5 & 3.6745 & $* * *$ \\
\hline CEP & Retail & 0.0885 & 1 & [14.4340] & $* * *$ \\
\hline GAN & Retail & 0.0044 & 9 & {$[0.6355]$} & \\
\hline $\mathrm{MCW}$ & Retail & 0.0299 & 3 & {$[2.2926]$} & $* *$ \\
\hline WFA & Retail & 0.0457 & 2 & {$[5.5376]$} & $* * *$ \\
\hline WFT & Retail & -0.0178 & 12 & {$[-2.1074]$} & $* *$ \\
\hline AIP & Industrial & -0.0185 & 13 & {$[-1.6892]$} & $*$ \\
\hline IIF & Industrial & 0.0189 & 7 & 2.4733 & $* *$ \\
\hline GHG & Hotel & -0.1702 & 18 & -12.2172 & $* * *$ \\
\hline THG & Hotel & -0.0271 & 16 & -0.9378 & \\
\hline ADP & Diversified & -0.0038 & 10 & -0.5233 & \\
\hline DDF & Diversified & -0.0190 & 14 & -1.8226 & $*$ \\
\hline GPT & Diversified & -0.0302 & 17 & -4.7527 & $* * *$ \\
\hline SGP & Diversified & 0.0225 & 6 & 2.3907 & $* *$ \\
\hline Avera & & -0.0028 & & & \\
\hline Positi & & 9 & & & \\
\hline Negat & & 9 & & & \\
\hline Signi & y Positive & 8 & & & \\
\hline Signi & y Negative & 6 & & & \\
\hline
\end{tabular}

In this study, a specific benchmark index has been derived for each of the LPTs to ensure that the market portfolio was precisely represented. Also, this study employed a non-linear specification of the evaluation model. Therefore, the absence of a strong negative correlation in this study comes as no surprise.

Also, the lack of importance of heteroscadasticity was found in the studies by Lee (1997), Henriksson (1984), and Chang and Lewellen (1984). However, in this study, the use of White (1980) in the presence of heteroscadasticity generated significantly different t-statistics compared with those based on non-adjusted OLS. 
For example, positive selectivity for WFT and positive timing for WFA became significant from insignificant after the adjustments.

\section{Selectivity and timing}

This study provides evidence regarding superior selectivity and timing abilities of Australian LPT managers over the period of June 1998 to May 2003.

As shown in Table 6, out of the 18 LPTs under evaluation, there are nine LPTs showing positive selection ability and eight of which show significantly positive selection ability. Managers with significant superior selection skills outnumbered those (6) with significant perverse selection ability.

In terms of timing, nine LPTs showed positive timing ability, six of which showing significantly positive timing ability. Again, managers with significant superior timing skills outnumbered that (only 1) with significant perverse timing skills.

Three LPTs present both significant superior selectivity and significant timing skills (MCW, WFA and IIF). MOF also shows positive selection and timing abilities, however only positive selectivity is significant.

\section{Performance decomposition and implications}

Following a CAPM framework, $\alpha$ in Jensen's model stands for the abnormal excess return achieved by a portfolio adjusted for its risk relative to the market portfolio. With the results from TM model, we can decompose this abnormal excess return into two components: selectivity and timing. For example, SGP showed an overall positive abnormal excess return of $2.25 \%$, which comprised of a significant positive selectivity component of $4.05 \%$ and a significant perverse timing component of $-1.80 \%$.

Table 8 presents this decomposition for all the LPTs evaluated in this study. At the aggregated level, selectivity appears to be a dominant driver to the abnormal excess returns compared with timing in the Commercial, Retail and Hotel sub-sectors. However, in the Industrial and Diversified sub-sectors, the role of timing increased significantly. For example, the positive abnormal excess returns achieved in the Industrial sector are solely attributable to positive timing, with perverse selectivity being recorded in this period.

A reasonable explanation as to why timing played a less significant role in the Commercial, Retail and Hotel sub-sectors is that LPTs in these sub-sectors are normally associated with large lumpy and thus less liquid assets. As a result, it often requires a relatively long time to execute any buy/sell decisions. So even if investment managers have good macro forecasting skills, the ability to apply such skills in a timely manner is limited in the practical sense. However, in the Industrial sector, assets involved are more liquid because the assets are normally smaller in size and less in value. Supply and demand of such assets are also less an issue 
compared with large lumpy assets. It is therefore less difficult for investment managers to apply their macro forecasting skills in the marketplace in this sector.

This highlights the importance of longer-term macro forecasts of market movements, especially in the circumstances where a lengthy time is required to apply timing skills. Managers who are superior in longer term macro forecasts and therefore will have sufficient time to apply timing skills to construct an optimal portfolio will have the edge to outperform the market portfolio and competitors.

The results from Table 8 also emphasised the importance of selecting the right properties, especially in circumstances where timing skills are less easy to exercise.

\section{Table 8: Selectivity and timing}

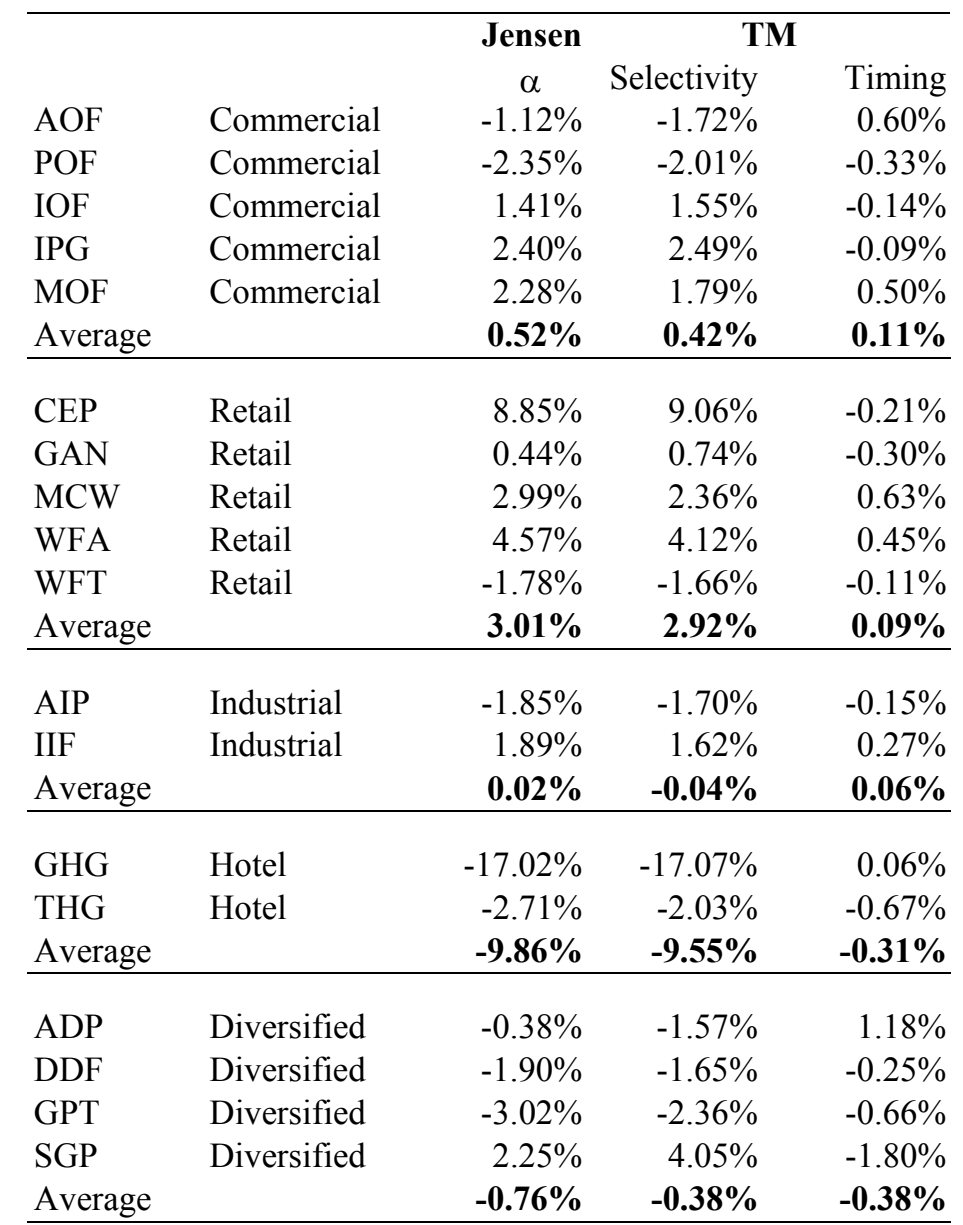




\section{Abnormal returns and performance measurement}

The results from Table 6 also have some implications for performance measurement. As a common practice in Australia, a LPT is normally claimed to outperform its benchmark if it has a higher return than its benchmark over a certain period and vice versa. Extra management fees are thus derived based on the magnitude of this out-performance. For example, for the period of June 1998 to May 2003, the annualised return for IOF is $8.7 \%$ (Table 2) and is thus 'under performed' against IOF's benchmark of 9.6\% (Commercial 300 excluding IOF, Table 3).

However, based on Jensen's model, IOF has a significant positive abnormal excess return $(\alpha)$ of $1.55 \%$, suggesting a significant 'out-performance'. The reason for these contradictory conclusions lies in whether the IOF return under measurement is risk-adjusted or not.

Recall that $\alpha$ in Jensen's model stands for the abnormal excess return achieved by a portfolio adjusted for its risk relative to the market portfolio. In this study, IOF has a $\beta$ of 0.599 in Jensen's model, therefore its expected excess return is $59.9 \%$ of the excess return generated by the market portfolio. That is, it only requires an excess return slightly higher than $59.9 \%$ of the excess return achieved by the market portfolio to record a positive abnormal excess return. This explains why IOF has an absolute return lower than its benchmark, but has a positive abnormal excess return against its benchmark at the same time.

For the same reason, IIF was found to significantly outperform its benchmark on the risk-adjusted basis (significant positive $\alpha$ ), but 'under perform' if the assessment was taken without adjustment for risk. However, POF is in contrast with this outcome. It 'outperformed' its benchmark on the face value, but underperformed on the risk-adjusted basis (significant negative $\alpha$ ).

Measuring fund performance based on risk-adjusted returns has significant practical implications. In the past, performance assessment has been too much focused on the absolute returns without any adjustments to the level of risks. Consequently, if a fund has its mandate and strategy to maintain a lower level of risk compared to its competitors, the performance of this fund will be underestimated and unfairly judged if the relatively lower level of risks has not been factored into the performance measurement. Similarly, there will be an overestimation on the true performance of an investment manager who takes higher risks to achieve higher absolute returns in order to 'outperform' the benchmark. 


\section{CONCLUSIONS}

In this study, the investment performance of 18 Australian LPTs was examined over the period of June 1998 through May 2003. A number of conclusions can be drawn from this study.

Firstly, it reinforced the importance of identifying and employing the appropriate benchmark indices in the evaluation of fund performance.

Secondly, it confirmed that Australian LPTs were actively managed over the study period and thus the risk level of the portfolio changed over time. In such a case, Jensen's model is not appropriate for selectivity tests, and selectivity and timing have to be jointly tested. Results from this study also supported the non-linear specification of portfolio returns.

Thirdly, this study provided evidence of superior strategic skills presented by Australian LPT managers over the study period. Managers with significant superior selectivity and timing skills outnumbered those with significant perverse selectivity and timing skills over this period.

Fourthly, this study decomposed portfolio abnormal excess returns into selectivity and timing. It analysed the relative importance of selectivity and timing to abnormal excess returns, and provided significant implications for strategic decision-makings.

Finally, this study illustrated why portfolio performance should be assessed on a risk-adjusted basis, providing significant practical implications for portfolio performance measurement.

\section{REFERENCES}

Admati, A., Bhattacharya, S. Pfleiderer, P. and Ross, S. (1986). Timing and selectivity. Journal of Finance, 41: 715-730.

Barkham, R. and Geltner, D. (1995). Price discovery in American and British property markets. Real Estate Economics, 23: 21-44.

Breen, W., Jagannathan, R. and Ofer, A. (1986). Correcting the heteroscadasticity in tests for market timing ability. Journal of Business, 59: 585-598.

Chan, A. and Chen, C. (1992). How well do asset allocation mutual funds managers allocate assets? Journal of Portfolio Management, 18: 81-91.

Chang, E. and Lewellen, W. (1984). Market timing and mutual fund investment performance. Journal of Business, 57(1): 57-72. 
Connor, G. and Korajczyk, R. (1991). The attributes, behaviour and performance of US mutual funds. Review of Quantitative Finance and Accounting, 1: 5-26.

Fama, E. (1972). Components of investment performance. Journal of Finance, 27: 551-567.

Gallo, J., Buttimer, R., Lockwood, L. and Rutherford, R. (1997). Determinants of performance for mortgage-backed securities funds. Real Estate Economics, 25: 657682.

Gallo, J., Lockwood, L. and Rutherford, R. (2000). Asset allocation and the performance of real estate mutual funds. Real Estate Economics, 28: 165-184.

Grant, D. (1977). Portfolio performance and the cost of timing decisions. Journal of Finance, 32(2): 837-46.

Henriksson, R. (1984). Market timing and mutual fund performance: an empirical investigation. Journal of Business, 57(1): 217-35.

Henriksson, R. and Merton, R. (1981). On market timing and investment performance II, statistical procedures for evaluating forecasting skills. Journal of Business, 54(4): 513-533.

Jagananthan, R. and Korajczyk, R. (1986). Assessing the market timing performance of managed portfolios. Journal of Business, 59: 217-235.

Jensen, M. (1968). The performance of mutual funds in the period of 1945-1964. Journal of Finance, 23: 389-416.

Jensen, M. (1972). Optimal Utilisation of Market Forecasts and the Evaluation of Investment Performance, in Szego and Shell, editors, Mathematical Methods in Investment and Finance, Amsterdam, North Holland.

Lee, S. (1997). The components of property fund performance. Journal of Real Estate Portfolio Management, 3(2): 97-105.

Lee, C. and Rahman, S. (1990). Market timing, selectivity and mutual fund performance: an empirical investigation. Journal of Business, 63(2): 261-78.

Lee, S. and Stevenson, S. (2002). A meta analysis of real estate fund performance. ARES Annual Meeting. 
Lee, S. and Stevenson, S. (2001). Empirical evidence on the micro and macro forecasting ability of real estate funds. Journal of Property Research, 20(3): 207234.

Liow, K. (2001). The abnormal return performance of Singapore property companies. Pacific Rim Property Research Journal, 7(2): 104-111.

Myer, F. and Webb, J. (2000). Management styles of REIT funds. Journal of Real Estate Portfolio Management, 6(4): 339-348.

Myer, F. and Webb, J. (1993). Return properties of equity REITs, common stock, and commercial real estate: a comparison. Journal of Real Estate Research, 8: 87106.

Newell, G., Lee, S. and Stevenson, S. (2003). The role of market timing and property selection in listed property trust performance. Pacific Rim Real Estate Society Conference 2003.

Newell, G. and MacFarlane, J. (1996). What does property trust performance tell us about commercial property returns? Australian Land Economics Review, 2(1): 10 18 .

O’Neal, E. and Page, D. (2000). Real estate mutual funds: abnormal performance and fund characteristics. Journal of Real Estate Portfolio Management, 6(3): 239 248.

PCA (2003) Investment Performance Index June 2003, Property Council of Australia.

Property Investment Research, (2003). Annual Listed Property Trust Review 2003. PIR: Melbourne.

RBA, (2002). Overnight Indexed Swap Rates. Reserve Bank of Australia Bulletin, June.

Seiler, M., Webb, J. and Myer, F., (1999). Diversification issues in real estate investment. Journal of Real Estate Literature, 7: 163-179.

Sharp, W. (1964). Capital asset prices: a theory of market equilibrium under conditions of risks. Journal of Finance, 19(3): 425-442.

Stevenson, S., Kinsella, R. and O’Healai, R. (1997). Irish property funds: empirical evidence on market timing and selectivity. Irish Business \& Administrative Research, 18: 163-176. 
Treynor, J. and Mazuy, K. (1966). Can mutual funds outguess the market? Harvard Business Review, 44: 131-136.

UBS Warburg (2003). Real Estate Monthly, June 1998 to June 2003.

White, H. (1980). A heteroscadasticity-consistent covariance matrix estimator and a direct test for heteroscadasticity. Econometrica, 48: 817-838.

Wilson, P. and Okunev, J. (1996). Evidence of segmentation in domestic and international property markets. Journal of Property Finance, 7(4): 78-97.

Wilson, P., Okunev, J. and Webb, J. (1998). Step interventions and market integration: tests in the US, UK and Australian property markets. Journal of Real Estate Finance and Economics, 16(1): 91-123. 